\title{
TAX CONSIDERATIONS IN INVESTMENT STRATEGIES: EVIDENCE OF FUNCTIONAL FIXATION ON ASSET DEPRECIATION
}

\author{
Richard L. Alltizer \\ Emporia State University \\ Emporia, KS \\ D. Elaine Sanders \\ The University of Texas - San Antonio \\ San Antonio, TX
}

\begin{abstract}
Tax planning strategies may encourage functional fixation on tax considerations in investment decisions. A desire to reduce income taxes payable may result in the irrational purchase of assets in order to keep depreciation on the income statement. In this case, fixation on tax, which is suggested by past literature involving functional fixation (Haka, Friedman, and Jones, 1986), could lead to sub-optimal decision-making in settings where after-tax income maximization would be the appropriate response. A controlled experiment was performed using M.B.A. students from a southwestern university. The presence or absence of information encouraging the development of a tax "frame" was the manipulated variable. The results support fixation on tax effects given a framing difference. In addition, a declining incidence of tax fixation was observed to correspond with years of business experience.
\end{abstract}

\section{Introduction}

The usefulness of accounting and other types of data to decision-makers depends not only upon the quality of the information but also upon the care with which it is used (Hopwood, 1974). Among important types of data that decision-makers consider in investment decisions are those relating to tax considerations. While tax planning is an important component of decision making in a business environment, over-emphasizing tax considerations in an investment decision may be a danger, that is, to the degree that other relevant data are not considered or weighted normatively. Considering the degree of importance of tax planning's influence on business and management, the effects of tax exposure on decision-making may be considered a prominent force in shaping the course of modern business.

Awareness of the influence of tax considerations on business decisions, though, raises questions regarding the factors that influence the decision-maker's strategies in weighing those factors. Decision-makers developing fixed responses based on tax considerations could affect their decision-making judgments, resulting in increasingly costly mistakes as decisions of greater materiality are made (Darrell, 1950). 
The lure of a quick tax dollar is often the only justification for a transaction that might have been accomplished with much sounder economic results and equivalent tax savings if more careful and deliberate consideration had been given to the problem (988-989).

An example of a fixed response based on tax considerations might include a businessman who purchases new equipment to replace fully depreciated, serviceable equipment.' The fact that depreciation expense is tax deductible may overshadow the fact that it is also a charge against income. Consider the following numerical example:

A businessperson currently owns a fully depreciated piece of equipment. The equipment is still serviceable and will remain so for the foreseeable future but has no salvage value. To avoid an increase in income taxes payable, this person is considering the purchase of a new asset to replace the old asset. The normative model for this decision would involve computing the net present value of the relevant differential costs in the decision. The investor will derive no benefit other than reduced income taxes from this asset. If the new asset costs $\$ 100,000$, is a fiveyear MACRS property, will have no salvage value, and the investor has a $40 \%$ tax rate and $16 \%$ cost of capital, then the net present value of the proposed investment would be $\langle \$ 72,989\rangle$. The computations are contained in Exhibit 1. The cost of the investment far outweighs the benefit in tax savings that will be obtained, and the normative decision would be to retain the old equipment.

Jones (1997) states that "tax deductions are a by-product of economic costs" which may be lost if the taxpayer eliminates (or reduces) the cost. Jones stresses that taxpayers should focus on controlling costs and not on the potential loss of tax benefits. Considering the possibility of sub-optimal decision processes, the potential cost to society of fixation on tax considerations becomes high. A pattern of inferior decisions in business could result in the misallocation and, ultimately, the waste of relatively scarce resources (Darrell, 1950).

The purpose of this research is to discern whether tax fixedness inhibits individual optimal decision-making processes. This issue will be addressed in the following sections. The next section contains the theoretical back-ground including the functional fixation and prospect theory literatures and the hypothesis. The third and fourth sections present the methodology employed in the experiment and the analyses and results. Conclusions and plans for future research are presented in the final section. 
Exhibit 1

Net Present Value Analysis

\begin{tabular}{|c|c|c|c|c|c|c|c|}
\hline Time & 0 & 1 & 2 & 3 & 4 & 5 & 6 \\
\hline \multicolumn{8}{|l|}{ Cash Flows } \\
\hline $\begin{array}{l}\text { Initial cost } \\
\text { of new asset }\end{array}$ & $(\$ 100,000)$ & & & & & & \\
\hline \multicolumn{8}{|l|}{$\begin{array}{l}\text { Depreciation } \\
\text { Tax Shield } \\
\text { (40\% Tax Rate) }\end{array}$} \\
\hline .20 & & $\$ 8,000^{*}$ & & & & & \\
\hline .32 & & & $\$ 12,800$ & & & & \\
\hline .192 & & & & $\$ 7,680$ & & & \\
\hline .1152 & & & & & $\$ 4,608$ & & \\
\hline .1152 & & & & & & $\$ 4,608$ & \\
\hline .0576 & & & & & & & $\$ 2,304$ \\
\hline Total Cash Flows & $(\$ 100,000)$ & $\$ 8,000$ & $\$ 12,800$ & $\$ 7,680$ & $\$ 4,608$ & $\$ 4,608$ & $\$ 2,304$ \\
\hline$P V I F$ & $\times 1.000$ & $\times .862$ & $\mathrm{x} .743$ & $x .641$ & $\mathrm{x} .552$ & $\times .476$ & $x .410$ \\
\hline \multicolumn{8}{|l|}{ Present Value of } \\
\hline Cash Flows & $(\$ 100,000)$ & $\$ 6,896$ & $\$ 9,510$ & $\$ 4,923$ & $\$ 2,544$ & $\$ 2,193$ & $\$ 945$ \\
\hline Net Present Value & $(\$ 72,989)$ & & & & & & \\
\hline
\end{tabular}




\section{Theoretical Background}

\section{Functional Fixation}

Strictly defined, functional fixation refers to the possible effects of repeated uses of data for a given purpose, followed by inhibition of the ability to adapt the data to other uses (Ashton, 1976). Kagan and Havemann (1976) also suggest that functional fixation is the tendency to make a given response to a given stimulus, as adapted to the function of an object. Further, Weisberg and Alba (1981) argue that the function an object serves is a limitation that we impose upon ourselves.

A simple example of functional fixation can be found when Duncker (1945) challenged subjects with a well-defined problem: attach three small candles to the wall. ${ }^{2}$ To accomplish this task, the subjects were given three small boxes, some tacks, a few matches, and three candles. In the fixation condition, the three small boxes held the candles, tacks, and matches. In the non-fixation condition, the items were simply scattered on a table top. When the items were held within the boxes, the boxes were designated as "containers" and the subjects were hesitant to use them as part of the experimental tools. When the items were scattered around, subjects much more quickly incorporated the boxes into their decision scheme by attaching the boxes (upside down) onto the wall with the thumbtacks and setting the candles on top.

By the same token, an individual who repeatedly uses earnings data for current valuation purposes might have trouble adapting the data to alternative uses, such as predicting future earnings, or a person who must continually strive to reduce income taxes may have trouble seeing an investment as an income increasing activity.

Evidence of functional fixation has also been documented in accounting contexts. Ashton (1976) and Swieringa, Dyckman, and Hoskin (1979) find that individuals who are fixated on accounting numbers are unable to change their use of that data when accounting changes occurred. Abdel-khalik and Keller (1979) test and find evidence of functional fixation in investment decisions using FIFO and LIFO changes.

Haka, et al. (1986) hypothesize that repeated exposure to cost measures might inhibit optimal decision responses by encouraging over-emphasis on cost data when market value data would be more relevant to the decision. The researchers note:

Fixation on cost and income data may leave individuals without the ability to discriminate, unaware of the appropriate contexts for the use of those data. That is, correct usage of market value data may become difficult for persons continually exposed to a variety of institutions demanding cost data (457).

Chang and Birnberg (1977) note that the issue of functional fixation is "whether the user exhibits a tendency to make a habitual response and, if so, whether he persists when he is informed of a change in the data inputs" (301). 
Further, Chang and Birnberg suggest two important issues involving accounting research and functional fixation: how past experience affects behavior and how to extinguish older, unnecessary patterns of behavior. The present study concerns itself with the former issue. To strengthen construct validity, this study examines the concept of tax fixedness at the expense of utility maximization in light of another area of relevant thought, prospect theory.

\section{Prospect Theory}

Prospect theory focuses on why individuals might violate widely accepted standards of rational choice. Tversky and Kahneman (1981) suggest that rational decision-making behavior involves consistency and requires that "preferences or utilities for particular outcomes should be predictive of the experiences of satisfaction or displeasure associated with their occurrence" (458). If this predictive nature of rationality is violated, sub-optimal consequences may result from lack of rationality in choices.

The importance of prospect theory to this study lies in three areas. First is the notion of "decision frames," a term that Tversky and Kahneman use to describe an individual's perception of acts, outcomes, and contingencies associated with a particular choice. Decision frames are "controlled partly by the norms, habits, and personal characteristics of the decision-maker" (453).

In framing a decision, decision makers establish the perspective that they will take for that decision. The process of framing includes defining the problem and deciding what is important to solve it. As the boundaries of the frame are set, some information will be included while some will be omitted; therefore, once a decision has been framed, the decision maker is left with only a partial view of the problem (Russo and Schoemaker, 1989).

Consider again the candle-mounting experiment presented earlier. When the boxes are framed as containers, subjects have difficulty considering them as shelves. When the boxes are just items on the table, however, they do not enter the problem with a specific frame and are summarily incorporated into the solution.

Second is the magnitude of change observed in the outcome relative to the decision maker's reference point. The reference point is set by the decision maker's perception of the problem context, or decision frame. An important precept of prospect theory is that the value function is steeper for losses than for gains.

That is, gains and losses of identical magnitude have different significance for people; the losses are considered more important. This makes intuitive sense from a functional perspective. A primary motive of virtually every organism is survival. Hypersensitivity to threats, for example, losses, would serve that motive well (Yates, 1990).

Finally, the result of the decision must be measured. An inappropriate decision that fulfilis the needs of the decision maker's frame will not be viewed as a 
decision failure by the decision maker. Still, the long-term effects of the decision could be devastating.

In the tax problem presented earlier, the decision maker can frame this problem in one of two ways: as a tax-reducing problem or as an income-increasing problem. If the decision is framed as a tax-reducing problem, the reference point will be set in reference to reducing tax dollars lost (the steep portion of the prospect curve). If the investment is made and income taxes payable decrease, the decision maker feels that the appropriate decision has been made.

In accordance with prospect theory, however, the decision maker has actually made his or her decision based on partial information. The overall effect of the transaction on the well-being of the company has not been fully considered.

The volume of tax strategy literature in contemporary business publications suggests that tax considerations will continue to play an important role in investment decisions for the foreseeable future. Thus, it is in society's interest to maximize the effectiveness of the decision-making skills of individuals whose decisions are influenced by tax considerations.

The emphasis in our society on cost and/or income could affect people's decision processes, resulting in a conditioning phenomenon..... Yet, social conventions, such as income taxes, which specify cost and income as crucial inputs, may cause people to react to this choice in unexpected ways. For example, if pervasiveness of cost data has changed simple decision-making behavior, one might observe a person choosing an item with a higher original cost even if it has a lower current value. If such behavior is widespread, there may be a high societal cost due to suboptimal decision-making behavior (Haka, et al., 1986, 456).

The current research question is: Does tax fixedness inhibit optimal decision-making processes in individuals? Prospect theory is easily transferable into tax research. If decision-makers frame a potential investment as a tax-savings strategy rather than as an income-maximizing strategy, the result could lead to an irrational decision. Conversely, if decision-makers are able to work with a potential investment choice without casting the problem into a taxation framework, they will make a more appropriate decision.

Given the literature regarding the effects of functional fixation and prospect theory, this study hypothesizes that (stated in the alternative):

Individual decision-makers will show a higher incidence of tax fixedness when an investment problem is framed as a tax problem than when it is not. 


\section{Methodology}

\section{Experimental Design}

To test the above hypothesis, the researchers designed and tested a role-playing case study. ${ }^{3}$ Subjects were cast into a scenario in which they assumed the role of a chemist with the opportunity of entering into a ten-year government contract. The only long-term asset the chemist would have to purchase would be an expensive delivery truck. ${ }^{4}$

In the "no-frame" condition, subjects were shown the estimated income statements for the first five years of the project (the depreciable life of the delivery truck). Subjects were then told that the budgeted income statements were an accurate reflection of actual business for the first five years. Further, although they had experienced no major difficulties with the delivery truck, the manufacturer had now (at the end of the fifth year) developed a new and improved delivery truck. A measure of probability was then taken of the subject's willingness to consider the purchase of a new delivery truck at this time.

The "tax-frame" condition simply extended the "no-frame" condition. After the subjects were told of the development of a new delivery truck by the manufacturer, they were presented with budgeted income statements for the remaining life of the contract. These income statements were prepared under the assumption that a new delivery truck would not be purchased, therefore depreciation expense ceased in the seventh year causing both income and income tax expense to increase. As in the "no frame" condition, a measure of probability was then taken of the subject's willingness to consider the purchase of a new delivery truck at this time. ${ }^{5}$

The experimental design, then, is a between-subjects randomized control group/manipulation group design (Exhibit 2).

\section{Exhibit 2}

\section{Experimental Design}

\begin{tabular}{|c|c|c|c|}
\hline $\begin{array}{l}\text { Experimental } \\
\text { Group }\end{array}$ & $\begin{array}{l}\text { Information } \\
\text { Set }\end{array}$ & $\begin{array}{l}\text { Additional } \longrightarrow \\
\text { Information }\end{array}$ & $\begin{array}{l}\text { Measure } \\
\text { Fixation }\end{array}$ \\
\hline $\begin{array}{l}\text { Control } \\
\text { Group }\end{array}$ & $\begin{array}{l}\text { Information } \\
\text { Set }\end{array}$ & $\rightarrow$ & $\begin{array}{l}\text { Measure } \\
\text { Fixation }\end{array}$ \\
\hline
\end{tabular}

The actual frame used by the subjects for their final decision is an internal state and cannot be accurately measured. To reject the null hypothesis, however, subjects in the "tax frame" condition should fixate on the role of depreciation expense as a method to reduce the income tax liability and should state a higher 
willingness to consider the purchase of a new delivery truck in order to keep depreciation on the income statement. In the "no frame" condition, the expiration of depreciation expense is not obvious, and the subjects should focus on the condition of the existing delivery truck and the increase in net income if a new delivery truck is not purchased. As a result, in the "no-frame" condition, the willingness to consider the purchase of a new delivery truck should be lower.

\section{Sample}

M.B.A. students at a southwestern university volunteered to serve as subjects for the study. They had completed at least one semester of graduate-level financial accounting and were currently enrolled in a graduate-level management accounting course.

Graduate students were considered to be an appropriate and useful subject group for this particular study. The students had all been exposed to and tested over the quantitative and qualitative aspects of net present value analysis, the depreciation tax shield, and cash flows needed to complete the task as presented.

\section{Procedure}

The experiment began with subjects completing a Statement of Informed Consent. After these statements were completed and collected, the instruments were randomly distributed to the subjects. The instrument consisted of the basic story contained in the case, a cash flow task, the functional fixation task, and the exit questionnaire. Subjects were given unlimited time to complete the instrument; however, the average time to complete was approximately 20 minutes.

\section{Data Analyses and Results}

A total of 152 subjects participated in the study. Information gathered on the exit questionnaire provided some demographic information about the subjects; $57 \%$ were male and $30 \%$ were international students. ${ }^{6}$ On average, the subjects had 1-5 years of actual business experience and $24 \%$ stated that they had occasionally or very often used income statement data in making business decisions.

Two subjects were dropped due to incomplete instruments. As a control measure for the contents of the scenario, subjects were asked to indicate whether the story suggested the need for a new delivery truck at the end of five years. In the scenario, subjects were told that no major problems had been encountered with the existing truck over the past five years. The purpose of this statement was to induce indifference between the two options. Eight subjects answered "yes" when asked if the company needed a new truck. A "yes" answer was interpreted as indicating that the subjects read more into the scenario than was actually presented, thus biasing their responses. Those eight subjects were subsequently dropped from the data set. 
The remaining 142 data points were analyzed using a $1 \times 2$ ANOVA with the stated probability of considering the purchase of a new delivery truck as the dependent measure and whether or not the subjects were encouraged to view the investment within a tax frame as the independent measure. The results of the analysis are presented in Table 1 . The results indicate a statistically significant effect $(a t a=10)$ for tax frame on the probability of considering the purchase of a new delivery truck $(F=3.31, p=0.0708)$.

Table 1

ANOVA Results for Tax Fixedness

\begin{tabular}{lcccc}
\hline & $\mathbf{n}$ & MEAN & SD & \\
No Frame & 71 & 42.66 & 34.01 & \\
Tax Frame & 71 & 53.08 & 34.22 & \\
\hline SOURCE & DF & SS & F VALUE & PR > F \\
Frame & 1 & 3856.34 & 3.31 & 0.0708 \\
\hline$(\mathrm{n}=142)$ & & & & \\
\hline
\end{tabular}

Subjects who were presented information more conducive to establishing a tax-frame for their decision stated a higher probability of considering the purchase of a new delivery truck than subjects who were presented with more openended information.

A problem with using an income statement format in an experimental instrument is the fact that depreciation, income tax, and net income all vary directly in relation to one another. If the subjects equated net income with cash flow, their probabilities of considering a new delivery truck could be tied to the perception of increased cash rather than fixation on decreasing the tax liability.

Thus, all subjects were asked a cash flow assessment question in the experimental instrument: to state their probabilities that a cash withdrawal of $\$ 20,000$ would be possible in each of the first five years. Because net income was less than $\$ 20,000$ for each of these years, subjects who equated cash flows with net income would state low probabilities for the desired withdrawal. On the other hand, actual cash flows were greater than $\$ 20,000$ in each of the first five years.

All subjects who stated a probability of less than $50 \%$ on the question of cash withdrawals were dropped from the data set on the assumption that they did not consider the actual cash flows in their final decision. As a result, 62 subjects were dropped from the sample, and the $1 \times 2$ ANOVA with the stated probability of considering the purchase of a new delivery truck as the dependent measure and 
whether the subjects were encouraged to view the investment within a tax frame as the independent measure was again computed. The results of the analysis (Table 2) indicate a statistically significant effect for tax frame (at $\alpha=.05$ ) on the probability of considering the purchase of a new delivery truck $(F=4.31$, $\mathrm{p}=0.0413$ ).

Table 2

ANOVA Results for Tax Fixedness

\begin{tabular}{lcccc}
\hline & $\mathbf{n}$ & MEAN & SD & \\
No Frame & 45 & 47.49 & 34.89 & \\
Tax Frame & 35 & 63.46 & 33.14 & \\
\hline SOURCE & DF & SS & F VALUE & PR $>$ F \\
Frame & 1 & 5020.02 & 4.31 & 0.0413 \\
\hline$(\mathrm{n}=80)$ & & & & \\
\hline
\end{tabular}

After controlling for knowledge of cash flows, subjects who were presented information more conducive to establishing a tax-frame for their decision still stated a higher probability of considering the purchase of a new delivery truck than subjects who were presented with more open-ended information. The implications of these results suggest that individual decision makers who frame investment questions with regard to the tax implications may favor investments that they see as tax reducers rather than as income maximizers.

Additional ANOVAs were used to observe the effect of information gathered from the exit questionnaire on the dependent variable. The independent variables were gender, international status, years of business experience, and frequency of income statement use for decision-making. The only variable that produced a statistically significant result was years of business experience $(F=2.73, p=$ 0.0354 ). Generally, the more years of experience the subject reported, the lower the probability of considering the purchase of a new truck. Table 3 presents the means for the five levels of experience and the comparison of those means using Tukey's Studentized Range test. 
Table 3

Means for Years of Business Experience

\begin{tabular}{lcccc}
\hline & n & MEAN & \multicolumn{2}{c}{ GROUP } \\
None & 16 & 63.13 & A & \\
Less than 1 year & 5 & 72.80 & A & B \\
1-5 years & 25 & 59.96 & A & B \\
5-10 years & 19 & 54.00 & A & B \\
More than 10 years & 15 & 30.60 & & B \\
Multiple comparisons using Tukey's Studentized Range test. & Different letters signify \\
statistically significant differences at p $<.05$. &
\end{tabular}

The data was tested again for interaction effects between years of experience and experimental condition. No interaction effects were found.

Main effects were then tested to ascertain whether the framing condition would still exhibit statistically significant differences after controlling for the effect of years of experience. The results are contained in Table 4. After controlling for years of experience, the effect of the frame manipulation on the dependent variable remains statistically significant $(F=5.76, p=0.0189)$.

\section{Table 4}

ANOVA Results for Tax Fixedness after Controlling for Years of Business Experience

\begin{tabular}{lcccc}
\hline SOURCE & DF & SS & F VALUE & PR $>$ F \\
Experience & 4 & 13215.60 & 3.15 & 0.0191 \\
Frame & 1 & 6052.78 & 5.76 & 0.0189 \\
\hline
\end{tabular}

While no hypothesis existed a priori to suggest a decline in functional fixation given years of business experience, it is interesting to note that this finding may be interpreted as paralleling Haka, et. al's (1986) results. In their study, they found age to be inversely related to fixation on selling prices. Older subjects were less likely to fixate on selling prices than younger subjects. In the current study, subjects with more years of business experience were less likely to fixate on tax-reducing investments than were subjects with no business experience.

\section{Conclusions}

The results obtained in this study suggest that individuals who fixate on the tax consequences of an investment decision are prone to make sub-optimal deci- 
sions. When information was provided to allow subjects to construct a tax-frame for considering an investment opportunity, those subjects found the opportunity much more appealing than did subjects who were presented open-ended information (no frame).

Additionally, years of business experience were found to relate inversely to the tendency to fixate on tax consequences. If years of business experience can be considered as a proxy for age, then this result supports the findings of Haka, et al. (1986).

While every effort was made to control internal and external variables that might have affected the results in this study, limitations do exist. In considering the purchase of the new truck, subjects were told that no major difficulties had been encountered with the existing truck to induce indifference between the two options. Further, subjects were asked in the exit questionnaire to disclose whether they believed a new truck was needed at this time. The subjects answering "yes" were dropped from the statistical analyses. Specific information about differences in the two trucks (potential cost reductions from lower fuel costs, lower repair costs, or lower maintenance costs) were not introduced into the scenario. A limitation of the study is the assumption that the two alternatives were equally weighted and that subjects were not considering other possible cost-related scenarios.

A second potential limitation of the study is the use of M.B.A. students as subjects. Ashton and Kramer (1980) suggest that students are an appropriate surrogate for professional decision makers in decisions requiring judgment and decision-making skills with no particular disciplinary expertise. A priori, the current study fit this requirement. Given the differences found among years of experience and probability of purchase, however, not using professional decision-makers may limit the ability to generalize the results.

Finally, the age of the references used in the study may be perceived as a limitation in this study, however, functional fixation in decisions of the nature presented here has not been a heavily researched topic in recent years. Haka, et al. (1986) is the latest paper to actually approach the issue of functional fixation from the viewpoint of interest to the current study.

As accountants, we should be keenly aware of the hazards of functional fixation on tax considerations. We should endeavor not to fall prey to this decision error as information providers [as would be dictated by interference theory (Haka, et al., 1986)], and we should be aware of the possibility of these fixating tendencies in our clients. By using normative decision-making procedures (e.g. emphasizing income increasing rather than income tax reducing strategies), we can present information in a manner conducive to optimal decision-making or help clients frame a decision to overcome decision problems like functional fixation. But to truly understand this problem, additional research must be conducted.

While the inverse relationship between years of experience and functional fixation supports the results of past research, additional research will assist in 
confirming those results. Instruments could more carefully measure business experience and extract specific details of that experience. Researchers could then verify the correlation between age and years of experience.

In addition, further study should be conducted specificaliy in the tax arena on the issue of functional fixation and its relationship to both investment strategies and tax avoidance strategies. While the current study casts subjects into the role of an individual making a self-profiting decision, additional research might cast them into an advisory role (tax or financial advisor). Differences may exist between the way an individual frames a decision given their external orientation.

Also, the effects of interference theory could be tested. While Haka, et al. (1986) found no evidence to support interference effects in their study, future research on tax issues could expand the search into the professional environment. One possible study would observe the fixation of students versus professionals. Additionally, different levels of students and professionals could be tested (Intermediate I students, Tax II students, Tax Accountants, and Financial Advisors).

In summary, support for functional fixation on tax consequences has been found in the controlled laboratory experiment conducted for this study. The potential of casting a decision into a tax frame has been shown to relate to that fixation, although years of experience seem to mediate fixative effects. Further research should be conducted to ascertain when and how fixation occurs. The results can help indiviual decision makers in overcoming this decision problem.

\section{Notes}

1. Economically, if he spends a dollar to receive a dollar's worth of reduction (replacing the equipment so as to receive a depreciation deduction), he is belter off only when the marginal tax rate exceeds 100 percent.

2. A thorough review of functional fixation can be found in Baron (1988), pages 47-51.

3. A synopsis of the experimental instrument follows in the appendix.

4. By entering into a government contract, we were able to suggest that all other costs and revenues would be constant over the life of the contract, thus eliminating conflicting issues that might have affected net income.

5. This task is analogous to a situation where a tax client's estimated tax liability suddenly increases due to the full-depreciation of assets. In this scenario, however, the client (subject) does not have an accountant telling him or her that the increase in taxes is directly correlated to the cessation of depreciation expense (which could enhance the fixation on the income tax effects of depreciation on the income statement). The omission of a detailed explanation of these effects, that is letting subjects frame the problem for themselves, biases against rejection of the null hypothesis and strengthens any statistically significant results that might be obtained.

6. Although no theory could be found to support differences in levels of fixation between U.S. and non-U.S. decision makers, a suggestion was made to the authors that the individual and corporate income tax structures in place in other countries might be reflected in the completion of the task by international students. Given this very 
relevant comment, a measure was taken of the international status of the subjects as a possible control variable.

\section{References}

Abdel-khalik, A.R., and T.F. Keller. "Earnings or Cash Flows: An Experiment on Functional Fixation and the Valuation of the Firm." Studies in Accounting Research \#16. Sarasota: American Accounting Association, 1979.

Ashton, R.H. "Cognitive Changes Induced by Accounting Changes: Experimental Evidence on the Functional Fixation Hypothesis." Journal of Accounting Research (Supplement 1976): 1-17.

Ashton, R., and S. Kramer. "Students as Surrogates in Behavioral Research: Some Evidence." Journal of Accounting Research 18 (1980): 1-13.

Baron, J. Thinking and Deciding. Cambridge: Cambridge University Press, 1988.

Chang, D.L., and J.G. Birnberg. "Functional Fixity in Accounting Research: Perspective and New Data." Journal of Accounting Research (Autumn 1977): 300-312.

Darrell, N. "Some Responsibilities of the Tax Adviser in Regard to Tax Minimization Devices." In Proceedings of the New York University Eighth Annual Institute on Federal Taxation. Albany, NY: Matthew, Bender \& Co., 1950: 988-989.

Duncker, K. "On Problem Solving." Psychological Monographs 58 (Whole No. 270), (1945).

Haka, S., L. Friedman, and V. Jones. "Functional Fixation and Interference Theory: A Theoretical and Empirical Investigation." The Accounting Review (July 1986): 455-474.

Hopwood, A.G. "Leadership Climate and the Use of Accounting Data in Performance Evaluation." The Accounting Review 49 (1974): 485-495.

Kagan, J. and E. Havemann. Psychology: An Introduction. New York: Harcourt Brace Jovanovich, 1976.

Jones, S. Federal Taxes and Management Decisions. Chicago: Irwin, 1997.

Russo, J.E. and P.J.H. Schoemaker. Decision Traps: The Ten Barriers to Brilliant Decision Making and How To Overcome Them. New York: Doubleday, 1989.

Swieringa, R.J., T.R. Dyckman, and R.E. Hoskin. "Empirical Evidence about the Effects of an Accounting Change on Information Processing." In Behavioral Experiments in Accounting II, ed. T.H. Burns. Ohio State University, 1979: 225-59. 
Tversky, A., and D. Kahneman. "The Framing of Decisions and the Psychology of Choice." Science 211 (1981): 453-458.

Weisberg, R.W., and J.W. Alba. "An Examination of the Alleged Role of 'Fixation' in the Solution of Several 'Insight' Problems." Journal of Experimental Psychology: General I10 (1981): 169-192.

Yates, J.F. Judgment and Decision Making. Englewood Cliffs, NJ: Prentice Hall, 1990.

\section{Appendix}

\section{A Synopsis of the Experimental Instrument}

\section{The Case}

As an aspiring young chemist, you have discovered a derivative of trinitrotoluene (tnt) that is a clearly superior form of the explosive. In the scientific community, your discovery has been nicknamed nt $^{2}$.

You have estimated that you can safely produce 200 units of $\mathrm{tnt}^{2}$ in a year. The Army Corps of Engineers (ACE) recently approached you with the offer of an exclusive contract for all 200 units of your product for each of the next ten years. ACE will pay you $\$ 1,000$ per unit for $\mathrm{tnt}^{2}$. In addition, $\mathrm{ACE}$ has offered to intervene on your behalf with potential chemical suppliers, allowing you to contract for a fixed per unit rate over the term of your ACE contract.

If you accept the ACE contract, you will only need to purchase one major piece of equipment: a specially-fitted delivery van for transporting the tnt $^{2}$. After checking with several potential manufacturers, you are confident that you can purchase the delivery van for approximately $\$ 100,000$.

You have enough cash on hand to begin manufacturing tnt $^{2}$, but you are still unsure whether the return on your investment is enough to justify the expenditure of your hardearned savings. So, you has taken the matter to your sister, Frieda, who is an accountant.

After reviewing the financial estimates and computing something called the "net present value" of the project, Frieda informed you that the project promises to offer you a return that is above your minimum expectations. In addition, Frieda has prepared estimated income statements for the next five years.

The projected income statements that Frieda prepared for the first five years are presented below. 
TNT $^{2}$

Estimated Income Statement For the Years 19x1 through 19x5

\begin{tabular}{|c|c|c|c|c|c|}
\hline & $19 \times 1$ & $19 \times 2$ & $19 \times 3$ & $19 \times 4$ & $19 \times 5$ \\
\hline $\begin{array}{l}\text { Sales } \\
\qquad(200 \text { units @ } \$ 1,000)\end{array}$ & $\$ 200,000$ & $\$ 200,000$ & $\$ 200,000$ & $\$ 200,000$ & $\$ 200,000$ \\
\hline $\begin{array}{l}\text { Cost of Goods Sold } \\
(200 \text { units } @ \$ 500)\end{array}$ & 100,000 & 100,000 & 100,000 & 100,000 & 100,000 \\
\hline Gross Margin & 100,000 & 100,000 & 100,000 & 100,000 & 100,000 \\
\hline Operating Expenses & 60,000 & 60,000 & 60,000 & 60,000 & 60,000 \\
\hline Depreciation Expense* & 20,000 & 32,000 & 19,200 & 11,520 & 11,520 \\
\hline $\begin{array}{l}\text { Operating Income } \\
\text { Before Income Taxes }\end{array}$ & 20,000 & 8,000 & 20,800 & 28,480 & 28,480 \\
\hline Income Taxes $(40 \%)$ & 8,000 & 3,200 & 8,320 & 11,392 & 11,392 \\
\hline Net Income & $\$ 12,000$ & $\$ 4,800$ & $\$ 12,480$ & $\$ 17,088$ & $\$ 17,088$ \\
\hline
\end{tabular}

Please consider the following questions independently.

Question 1.

You wish to withdraw $\$ 20,000$ each year for personal use. Given the information furnished above, what is the probability that you will have the required amount of cash available in each of the first five years?

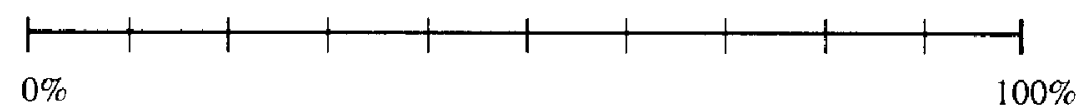

Mark your response with a slash (/).

\section{No-Frame Condition}

Question 2.

Frieda's estimates were a close approximation of the actual business for $\mathrm{TNT}^{2}$, and you have experienced no major difficulties in either the production or delivery of $\mathrm{tnt}^{2}$ during the first four years. In $19 \times 5$, the manufacturing company from which you bought the delivery truck informed you that they had developed new systems which they believed would improve the performance of a new van, should you decide to purchase one. Given the information provided above, what is the probability that you would consider the purchase of a new van?

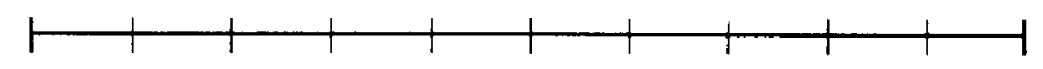

$0 \%$

Mark your response with a slash (/). 


\section{Frame Condition}

Question 3.

Frieda's estimates were a close approximation of the actual business for $\mathrm{TNT}^{2}$, and you have experienced no major difficulties in either the production or delivery of tnt 2 during the first four years. In preparation for the next five years of production, you have asked Frieda to once again prepare budgets. The projected income statements for years $19 \times 6-19 y 0$ are presented below.

TNT $^{2}$

Estimated Income Statement For the Years 19x6 through 19y0

\begin{tabular}{|c|c|c|c|c|c|}
\hline & $19 \times 6$ & $19 \times 7$ & $19 \times 8$ & $19 \times 9$ & $19 \mathrm{y} 0$ \\
\hline $\begin{array}{l}\text { Sales } \\
\qquad(200 \text { units @ } \$ 1,000)\end{array}$ & $\$ 200,000$ & $\$ 200,000$ & $\$ 200,000$ & $\$ 200,000$ & $\$ 200,000$ \\
\hline $\begin{array}{l}\text { Cost of Goods Sold } \\
\text { (200 units@ @ } \$ 500)\end{array}$ & 100,000 & 100,000 & 100,000 & 100,000 & 100,000 \\
\hline Gross Margin & 100,000 & 100,000 & 100,000 & 100,000 & 100,000 \\
\hline Operating Expenses & 60,000 & 60,000 & 60,000 & 60,000 & 60,000 \\
\hline Depreciation Expense* & 5,760 & 0 & 0 & 0 & 0 \\
\hline $\begin{array}{l}\text { Operating Income } \\
\text { Before Income Taxes }\end{array}$ & 34,240 & 40,000 & 40,000 & 40,000 & 40,000 \\
\hline Income Taxes (40\%) & 13,696 & 16,000 & 16,000 & 16,000 & 16,000 \\
\hline Net Income & $\$ 20,544$ & $\$ 24,000$ & $\$ 24,000$ & $\$ 24,000$ & $\$ 24,000$ \\
\hline
\end{tabular}

In $19 \times 5$, the manufacturing company from which you bought the delivery truck informed you that they had developed new systems which they believed would improve the performance of a new van, should you decide to purchase one. Given the information provided above, what is the probability that you would consider the purchase of a new van?

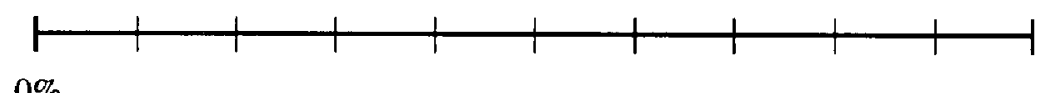

$0 \%$

$100 \%$

Mark your response with a slash (/).

Dr. Richard Alltizer, (Ph.D., University of Oklahoma) spent 14 years in public accounting before earning his Ph.D. He is currently an assistant professor at Emporia State University in Emporia, Kansas. Dr. Alltizer teaches a variety of tax issues and has developed numerous continuing education courses in tax. He has published tax-related re- 
search in Taxation for Accountants, Taxation for Lawyers, and the Journal of Applied Business Research.

Dr. Elaine Sanders, (Ph.D., University of Oklahoma) received her Ph.D. after working in the private sector. She is currently an assistant professor at the University of Texas at San Antonio in San Antonio, Texas. Dr. Sanders teaches financial and managerial topics in accounting. Her research interests focus on the use of accounting information for decision-making which enables her to conduct research across a broad range of accounting topics. Dr. Sanders has published in the Journal of Accounting Case Research. 